\title{
Impactos asociados al turismo en la comunidad de José María Morelos, Jalisco, México
}

\author{
Emma Lizeth Noriega Garza* Stella Maris Arnaiz Burne** \\ Universidad de Guadalajara (México)
}

\begin{abstract}
Resumen: En la comunidad el turismo de naturaleza fue el detonador de la actividad, sin embargo, las políticas públicas desde el inicio del siglo XXI se han enfocado en impulsar megadesarrollos turísticos que han causado diversos impactos, por lo que se analizaron los cambios percibidos por los pobladores a raíz de los nuevos proyectos, en el año 2009 con respecto al 2019, considerando problemas sociales, actividad turística e impactos en la comunidad. Se aplicó una encuesta con el método de muestreo de racimo que se analizó con el método del Ábaco Régnier y estadística descriptiva. En 2009, los dos problemas sociales más urgentes fueron: agua potable y servicios médicos, y el de mayor motricidad fue la organización social. El impacto positivo más percibido asociado al turismo fue el empleo y el impacto negativo la contaminación. En 2019 se conservó la tendencia, confirmando que el empleo es percibido como el impacto turístico más positivo para la comunidad.
\end{abstract}

Palabras Clave: Sustentabilidad; Desarrollo; Progreso; Comunidad anfitriona; Percepción; Trabajo y pobreza.

\section{Impacts associated with tourism in the community of José María Morelos, Jalisco, México}

Abstract: In the community, nature tourism was the trigger for the activity; however, public policies since the beginning of the 21st century have focused on promoting tourism megadevelopments that have caused various impacts, so the changes perceived by the inhabitants were analyzed as a result of the new projects, in 2009 compared to 2019, considering social problems, tourism activity and impacts on the community. A survey was applied with the cluster sampling method that was analyzed with the Régnier Abacus method and descriptive statistics. In 2009 the two most urgent social problems were: potable water and medical services, and the one with the greatest mobility was the social organization. The most perceived positive impact associated with tourism was employment and the negative impact was pollution. In 2019 the trend was preserved, confirming that employment is perceived as the most positive tourist impact for the community.

Keywords: Sustainability; Development; Progress; Host community; Perception; Work and poverty.

\section{Introducción}

Inversamente de que el turismo se ha convertido en una de las principales actividades económicas de México y es un paradigma de desarrollo en muchas regiones, no se han logrado los niveles de planeación y gestión a corto, mediano y largo plazo. Aún menos se considera la premisa de la participación social; factor esencial para potenciar esta actividad en lo económico, cultural, social y ambiental si se pretenden alcanzar los horizontes hacía la sustentabilidad del turismo en sus diversas conceptualizaciones.

El estado de Jalisco es la cuarta entidad más poblada del país, sus problemas demográficos se relacionan con la distribución desigual de la población en su territorio que se manifiestan en dos fenómenos opuestos: la concentración y la dispersión. La Costalegre del estado de Jalisco es una de las pocas fronteras existentes, de cara a los procesos de desarrollo turístico vertiginoso que sufren otras regiones costeras del país, su repoblación se inició en los años 40's, en tanto que su crecimiento

* Universidad de Guadalajara (México); E-mail: emmanoriega24@gmail.com; https://orcid.org/0000-0002-0764-2108
** Universidad de Guadalajara (México); E-mail: stellaarnaiz@yahoo.com.mx; https://orcid.org/0000-0002-6366-2218 
demográfico se aceleró en la década de los años 60's como consecuencia de la dotación de tierras ejidales dirigida a pobladores de otras regiones, quiénes en esa época solicitaron ampliación de sus ejidos, o bien, dotación de tierras por ser sujetos de derechos a salvo de acuerdo a la legislación aplicable en la época. Tal forma de dotación de tierras acarreó, entre otras cuestiones, la fundación de nuevos centros de población ejidal en la Costalegre, en los cuales han surgido confrontaciones de intereses individuales, grupales, culturales y/o económicos, que ha permeado en el tiempo obstaculizando el desarrollo de la región hacia objetivos básicos comunes.

La localidad José María Morelos se constituyó por resolución presidencial en 1960 en la que se autorizó la creación del Nuevo Centro de Población Ejidal (NCPE), en el municipio de Tomatlán, con una superficie de 12,400,00-00 has. con diversas calidades, en beneficio de 387 campesinos (DOF, 1960).

En la región de la Costalegre del estado de Jalisco desde los años 60`s la actividad turística ha estado presente en sus diferentes modalidades de turismo no masivo. La región y la localidad de José María Morelos, por su biodiversidad y fragilidad ambiental, se consideran idóneas para el desarrollo de turismo de bajo impacto. Desde el inicio del siglo XXI se incrementó la promulgación de planes y programas gubernamentales que pretenden impulsar el desarrollo ordenado y sustentable de la actividad turística mediante la generación de productos integrales que promuevan el aprovechamiento de los principales atractivos naturales y culturales de la zona.

\section{Marco Teórico}

Según Pulido (2008, pág. 25) el turismo se destaca al menos por tres singularidades: 1).-En el turismo el propio espacio juega un papel fundamental para todos y cada uno de los agentes que intervienen en los procesos de producción-consumo; 2).- La dialéctica propia entre espacio y turismo se manifiesta en dos hechos: el primero, el producto no se desplaza, se consume allí donde se produce y, además no desaparece; segundo, el consumo y la producción turística se dan simultáneamente; y 3).- Además del proceso de producción física, existe una producción de carácter simbólico a través de la valoración social de la imagen turística.

Por su parte Luigi Cabrini, Director de Desarrollo Sostenible del Turismo de la Organización Mundial del Turismo, planteó que "el papel del turismo como motor clave del crecimiento económico, especialmente en países en desarrollo y entre los menos adelantados, está cada vez más reconocido" (OMT, 2011).

Generalmente el turismo goza de dos amplias clasificaciones basadas esencialmente en el número de turistas y en la visión económica: el turismo de masas y el turismo alternativo, conceptualizaciones que mantienen una relación de interdependencia, debido a que aquel turismo que no se conceptúa como de masas, se le traslada a la categoría de turismo alternativo y a la inversa. Ahora bien, en el caso del turismo de masas, su valor se determina por la derrama económica que genera en los destinos turísticos, en tanto que en el turismo alternativo su valor se focaliza en la conservación del entorno natural, cultural y social de los destinos, por tanto, el aspecto económico no se lo considera preponderante, salvo para el efecto de su rentabilidad financiera que posibilite su sustentabilidad (Mieczkowski citado por Wearing y Neil, 2000). Sin embargo, debe reconocerse el carácter poliédrico del turismo, que más allá de una actividad económica, es una práctica social que ha sido abordada por distintas disciplinas, con múltiples acotaciones, enfoques y definiciones (Pulido, 2008).

Dentro de la multiplicidad de acepciones acerca del turismo de masas, Wearing y Neil (2000, pág. 23) lo definen como aquel que "atrae de forma masiva turistas, sin importar nivel económico y exigencia del turista, la modalidad más tradicional del turismo de masas es el denominado turismo de sol y playa".

A su vez, al turismo alternativo se le ha considerado como la antítesis del turismo de masas, se le conceptúa como "el conjunto de modalidades turísticas que tienen por objetivo ser consecuentes con los valores naturales, sociales y comunitarios, permitiendo además, tanto a los anfitriones como a los huéspedes, disfrutar de una interacción positiva, así como de las experiencias compartidas" (Wearing \& Neil, 2000, pág. 24). Es significativo resaltar que se da y se puede dar cierto solapamiento en las diversas acepciones del turismo alternativo, es decir, que una actividad relacionada con el turismo rural puede coincidir en espacio, con otra relacionada con el ecoturismo.

A principios de la década de los 90's es cuando se plantea la sustentabilidad en el turismo. Según Villanueva (2000) el turismo sustentable "busca minimizar los impactos sobre los ecosistemas en respuesta al uso de los recursos naturales por actividades turísticas y asimismo procura la conservación de la cultura y las tradiciones del destino". 
La Carta del Turismo Sostenible aborda al turismo desde una perspectiva holística "en la que se reconoce la necesidad de desarrollar turismo que satisfaga las expectativas económicas, las exigencias ambientales y que sea respetuoso con las poblaciones receptoras" (Conferencia Mundial de Turismo Sostenible, 1995).

Las administraciones públicas (a nivel local, estatal, regional y nacional) han instrumentalizado y potencializado la actividad turística como factor de desarrollo de los espacios rurales, ya que incorporan la puesta en valoración turística del patrimonio natural y rural como estrategia para diseñar planes para el desarrollo de productos turísticos no convencionales, exclusivos y de alta plusvalía (Pulido, 2008).

Entonces, el turismo rural se clasifica como parte del turismo alternativo, ya que ofrece productos turísticos no masivos y se justifica e instala bajo el paradigma de la sostenibilidad. El concepto turismo rural es polisémico; sin embargo, sus diversas acepciones lo caracterizan por su dependencia en la realización de actividades-experiencias exclusivas del espacio rural. Por lo que el desarrollo del turismo en espacios rurales puede actuar como agente catalizador de los procesos de transformación y modernización (Pulido, 2008).

Es habitual explicar las bondades del turismo y sus beneficios, pero también se han llevado a cabo interpretaciones con la finalidad de desmitificar los resultados acerca de las intervenciones de las administraciones públicas para impulsar y desarrollar la actividad turística en espacios rurales, las cuales han realizado críticas sobre los impactos del turismo en el mundo rural y alertan sobre su alcance real en la sociedad que lo habita (Pulido, 2008).

\section{Metodología}

La información estadística se obtuvo directamente de los pobladores de la localidad José María Morelos, a través de la aplicación de encuestas a una muestra representativa de la población, aplicando el método de muestreo de racimo en el que se agrupó a la población según el número total de viviendas habitadas. Además se utilizó un plano de la localidad, para dividir el territorio en manzanas y se escogieron un número de éstas (racimos) para entrevistar a sus habitantes (Levin \& Rubin, 1996).

$$
\text { Fórmula aplicada: } \quad n=\frac{N * Z_{\alpha}^{2} p * q}{d^{2} *(N-1)+Z_{\alpha}^{2} * p * q}
$$

Donde:

$$
\begin{aligned}
& n=\text { Total de la población } \\
& Z_{\alpha}^{2}=\text { Nivel de confianza } \\
& p=\text { Proporción esperada } \\
& q=1-p \\
& d=\text { Error estándar }
\end{aligned}
$$

El proceso de recolección de datos consistió en recorrer los cuatro sectores de la localidad (previamente divididos en el plano oficial) y luego seleccionar al azar las viviendas. Por lo anterior, para la obtención de la información se aplicaron encuestas al azar a una muestra representativa de 199 pobladores de 15 años o más en el año 2009 y, de 200 pobladores en el año 2019. Considerando que el tamaño del universo, en el 2010, fue de 738 viviendas habitadas y, en el año 2019 fue de 742 viviendas habitadas. Con un error máximo aceptable del 5\%, porcentaje estimado de la muestra de 50\% y un nivel de confianza del 90\%, el resultado del cálculo sería: 199 encuestas en 2009 y 200 encuestas en 2019.

Después de la consulta e interrogación a los habitantes (los expertos) de la localidad de acuerdo con el método concebido por François Régnier, con el fin de que expresarán sus percepciones y respuestas, las cuales posteriormente se agruparían en una escala de colores (Godet, 2007, pág. 80).

Después de recabar todas las opiniones de los expertos se procedió a enlistar sus afirmaciones expresadas, para luego utilizar la lógica de los colores del semáforo para la elaboración de un ábaco (verde, amarillo y rojo), complementado con el verde claro, el rojo claro (que permiten suavizar las opiniones). El blanco significó la abstención, por lo tanto, se obtuvo una escala de decisiones coloreadas (Godet, 2007, pág. 80). 
Las respuestas obtenidas y coloreadas en forma de matriz se representaron: en filas, los ítems que definen los problemas sociales y, en columnas, las opiniones de los expertos que participaron en el estudio. La imagen del mosaico constituye un panorama de información cualitativa, siendo visible -simultáneamente- la posición de cada uno de los expertos sobre los problemas sociales de la localidad (Godet, 2007, pág. 81).

La matriz estructural se elaboró con los 10 problemas prioritarios detectados, comparándolos entre ellos con el propósito de identificar sus posibles relaciones; dándole valor de 1 si existía relación y 0 cuando no la hubo, la sumatoria representó la dependencia total entre los problemas (Godet, 2007, pág. 81).

Para calcular porcentualmente la esperanza matemática de la motricidad y dependencia como resultado de determinar el valor que tuvo cada problema, en el caso que fuera totalmente independiente. El procedimiento fue el siguiente:

$$
E n=100
$$

Donde, $E=$ esperanza matemática, $n=$ número de problemas.

Luego se procedió a elaborar un sistema de coordenadas (con los datos obtenidos en la matriz estructural) para identificar los problemas que tienen mayor influencia (motricidad) y los que aparecen como consecuencia de aquellos (dependencia) (Godet, 2007, pág. 81).

$\mathrm{Al}$ inscribir los problemas en un plano cartesiano, cuyos ejes fueron las dimensiones de motricidad y dependencia, se produjeron cuatro áreas:

1) Poder: Alta motricidad y baja dependencia.

2) Conflicto: Alta motricidad y alta dependencia.

3) Autonomía: Baja motricidad y baja dependencia.

4) Salida: Baja motricidad y alta dependencia.

Asimismo, del último apartado de la encuesta se obtuvo la percepción y opiniones de la población acerca del turismo; información relacionada con el acogimiento de familiares o amigos que disfrutan de su tiempo de descanso en la localidad, el interés por parte de la persona encuestada en prestar servicios turísticos y las opiniones del principal beneficio que cree que emana del turismo y el impacto negativo que pueden generar los turistas. De lo anterior se obtuvieron datos estadísticos descriptivos a partir de los cuales se elaboraron gráficos.

\section{Caso de Estudio}

El Instituto Nacional de Estadística y Geografía (INEGI) ubica al estado de Jalisco como la cuarta entidad más poblada de México, un Estado con problemas demográficos relacionados con la distribución desigual de la población manifestados en dos fenómenos opuestos: la concentración y la dispersión; que han originado segregación social, degradación ambiental y limitado el desarrollo de las regiones con menos densidad poblacional. La dispersión de la población rural jalisciense sobrepasa el millón de personas que viven en localidades menores de 5,000 habitantes (INEGI, 2016). Tal fenómeno limita la dotación de servicios básicos, servicios de salud, educación y la inversión, es decir, propicia el aislamiento de las zonas rurales.

La región de la Costa Alegre del estado de Jalisco es una de las áreas consideradas de mayor dispersión poblacional, menor crecimiento económico y desarrollo en comparación con otras regiones costeras. En los años 40's inició su colonización, en tanto, en la década de los años 60's se aceleró su crecimiento demográfico derivado de los decretos presidenciales publicados en favor de ampliaciones ejidales o dotación de tierras a sujetos con derechos a salvo (César Dachary \& Arnaiz Burne, 2004). Por lo anterior fue necesaria la fundación de nuevos centros de población ejidal, también denominados localidades.

El 12 de abril de 1960, por Resolución Presidencial, se constituyó el Nuevo Centro de Población Ejidal (NCPE) denominado José María Morelos, en el municipio de Tomatlán, con una superficie de tierras de 12,400,00-00 has. con diversas calidades (Tabla No. 1), beneficiando a 387 personas, distribuidas de la siguiente manera: 
Tabla N. ${ }^{\circ}$ 1: Distribución de superficies del NCPE José María Morelos.

\begin{tabular}{|l|l|}
\hline Calidad de los Terrenos & Extensión \\
\hline Terrenos Laborables & $\begin{array}{l}7,760.00 .00 \text { has. (20.00.00 has. para cada ejidatario y para la } \\
\text { escuela del lugar) }\end{array}$ \\
\hline Zona de urbanización & 300.00 .00 has. \\
\hline Terrenos de usos colectivos & $4,340.00 .00$ has. \\
\hline
\end{tabular}

Fuente: (DOF, 1960)

La localidad de José María Morelos (Ilustración No. 1 y N. ${ }^{0}$ 2) se ubica al suroeste de la cabecera municipal denominada Tomatlán, las coordenadas geográficas de la localidad son: $19^{\circ} 40^{\prime} 35^{\text {” latitud }}$ norte y $105^{\circ} 10^{\prime} 56^{\prime \prime}$ longitud oeste; con una altitud de 9 metros sobre el nivel medio del mar (INEGI, 2011). Las localidades cercanas a José María Morelos son: Al norte Campo Acosta, al sur Quémaro, al este Higuera Blanca y al oeste el océano Pacífico.

\section{Ilustración N. ${ }^{\circ}$ : Plaza de Armas}

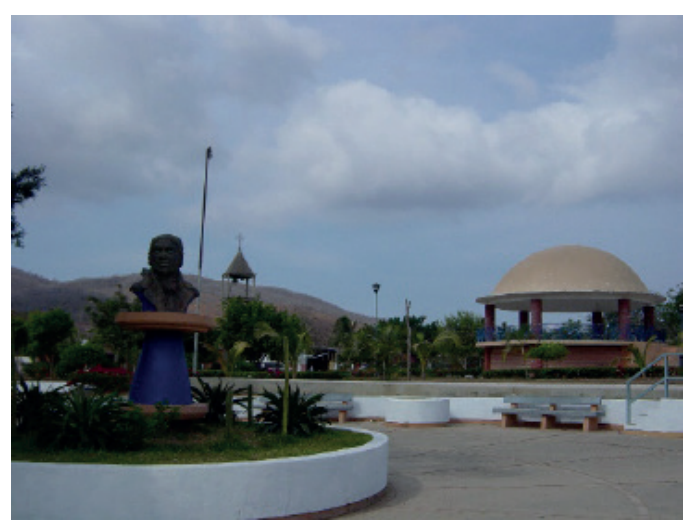

\section{Ilustración N.ㄹ 2 : Vista de la localidad}

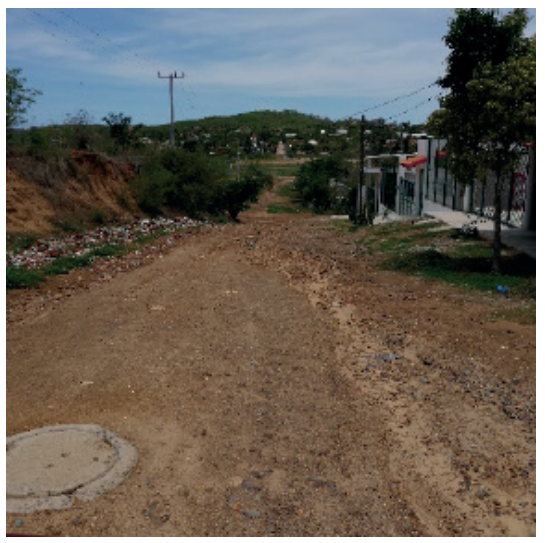

La localidad José María Morelos conserva desde 1980 una categoría política indefinida, ni urbana ni rural, ya que no cuenta con el decreto o reconocimiento oficial necesario (INEGI, 2011). 
Tabla N. ${ }^{\circ}$ 2: Categorías Políticas de la Localidad José María Morelos.

\begin{tabular}{|c|c|}
\hline Categoría Política & Origen de la modificación \\
\hline Ranchería & Censo de 1970 \\
\hline Indefinida & Censo de 1980 \\
\hline Indefinida & Censo de 1990 \\
\hline Indefinida & Conteo de 1995 \\
\hline Indefinida & Censo de 2000 \\
\hline Indefinida & Conteo de 2005 \\
\hline Indefinida & Censo de 2010 \\
\hline
\end{tabular}

Fuente: (INEGI, 2011)

En el año 2006 culminaron las gestiones administrativas por parte del Gobierno del Estado para la construcción y operación de una aeropista en la Costa Alegre, ubicada en el kilómetro 104 de la carretera Federal 200: Puerto Vallarta-Barra de Navidad, con la aprobación de este proyecto se fortaleció la especulación inmobiliaria, en particular se impulsó la compraventa de terrenos propiedad de los ejidos José María Morelos y Campo Acosta.

Para la aeropista se destinó una superficie total de 136.86 has., distribuida en: una pista asfaltada de $2200 \mathrm{mts}$. de largo, $45 \mathrm{mts}$. de ancho, así como una plataforma, una terminal aérea de pasajeros, un edificio de operaciones, un camino de ingreso, un estacionamiento y áreas de servicios. Los aviones de pasajeros que podrán utilizar la pista serán los siguientes modelos: MD-87, MD-82/83/88 y Boeing 737-700. El tránsito estimado de aeronaves en la aeropista se consideró un máximo de 10 operaciones al día, con la esperanza que se incrementará con el paso del tiempo (AyMA Ingeniería y Consultoría S.A. C.V., 2006).

Desde el 2012, a través del Programa Subregional de Desarrollo Turístico Costalegre, el Gobierno del Estado impulsa el desarrollo de la actividad turística, anhelando que surjan productos turísticos integrales que promuevan el aprovechamiento sustentable de la costa y sus principales atractivos naturales y culturales. Para el año 2030 proyectan que se consoliden los siguientes segmentos turísticos con su respectiva participación porcentual en la afluencia total esperada: turismo de sol y playa: $46.8 \%$, turismo de naturaleza: $20 \%$, turismo premium: $17.5 \%$, turismo de congresos y convenciones: $7.5 \%$, turismo de retirados: $5 \%$ y turismo cultural: $3.2 \%$ (Gobierno de Jalisco, 2012).

Después de la aeropista, el "Proyecto Desarrollo Vistas" es la intervención público-privada más importante, el cual es impulsado desde el 2012 por el Instituto de Pensiones del Estado de Jalisco, Paraland S. de R.L. de C.V., Chalalegre S. de R.L. de C.V. y Chalamar S. de R.L. de C.V. el cual fue planeado en la playa Chalacatepec (Ilustraciones No. 3) como un desarrollo turístico de tipo mixto: hotelero, residencial, comercial y deportivo con una extensión superficial de 1,178.21 has. a realizarse en el periodo de 99 años. La densidad del proyecto se contempló con 8,192 cuartos y la superficie total de aprovechamiento se estableció en 212.23 has. equivalentes al $18.01 \%$ del terreno. Desde su concepción pretende generar experiencias turísticas relacionadas con un desarrollo sustentable que permita al huésped, visitante o habitante disfrutar del auténtico estilo de vida de la región, beneficiar de manera directa a los pobladores locales y, en armonía y respeto al medio ambiente (ACTUROP S. de R. L. de C. V., 2012). Al mes de julio del 2019 por parte del Desarrollo Vistas se habían realizado principalmente trabajos de trasplante de palmeras en la línea colindante a la zona federal marítimo terrestre y el área de dunas, así como la instalación de un vivero (Ilustraciones No. 4).

\section{Resultados y Análisis}

Del total de habitantes encuestados en el 2009 el $69 \%$ fueron mujeres y el 31\% hombres, la edad promedio fue de 38 años. El 75\% de los encuestados no nacieron en la localidad José María Morelos y el promedio de residencia fue de 23 años. En el 2019 del total de habitantes encuestados el 64\% fueron mujeres y el 36\% hombres, la edad promedio fue de 39 años. El 64\% de los encuestados no nacieron en la localidad y el promedio de residencia fue de 30 años. 


\section{Ilustración 3: Playa Chalacatepec}

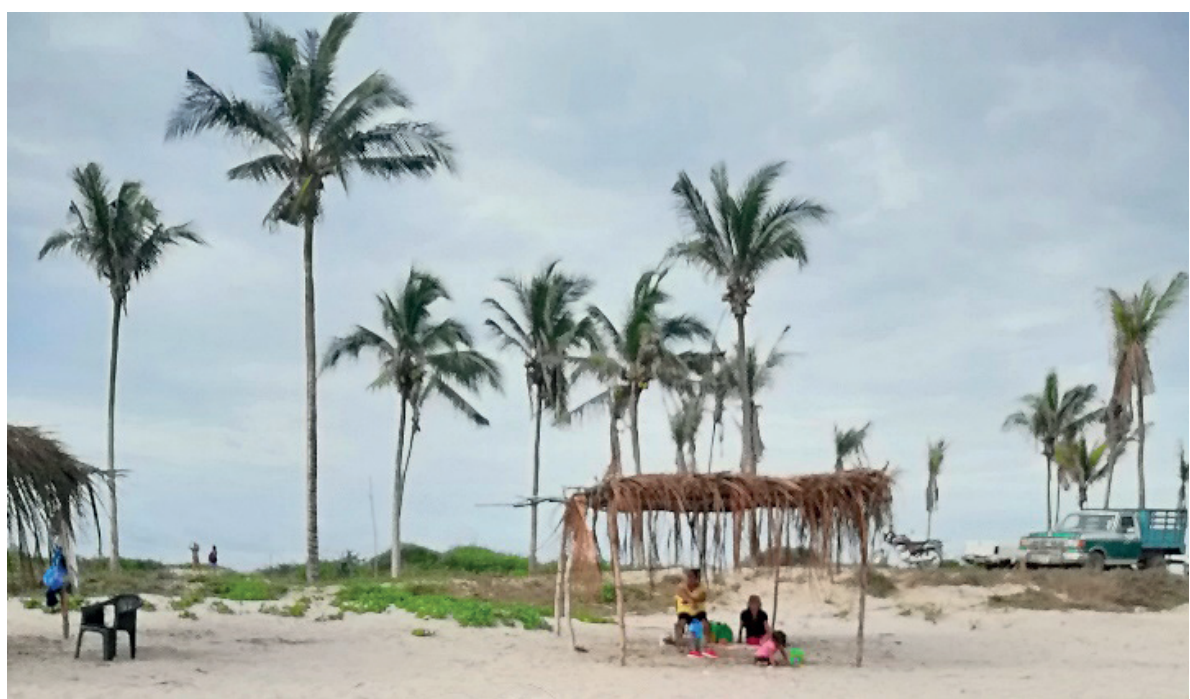

Ilustración 4: Avances del Proyecto Desarrollo Vistas

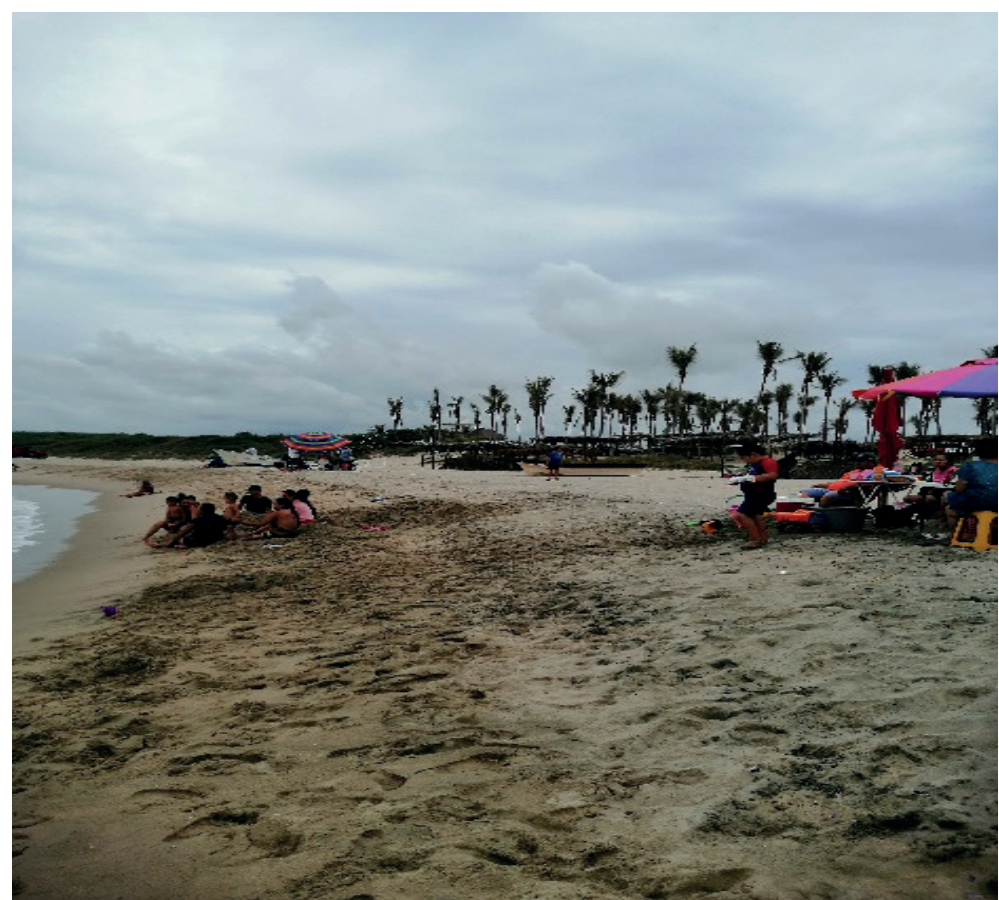

En relación al nivel de estudios de las personas encuestadas en el 2019 se registró un menor número de personas sin estudios asimismo se incrementó el número de personas con estudios de secundaria y licenciatura (Gráfica N. ${ }^{\circ}$ 1). 
Gráfica N. ${ }^{\circ}$ 1: Nivel de escolaridad de las personas encuestadas.

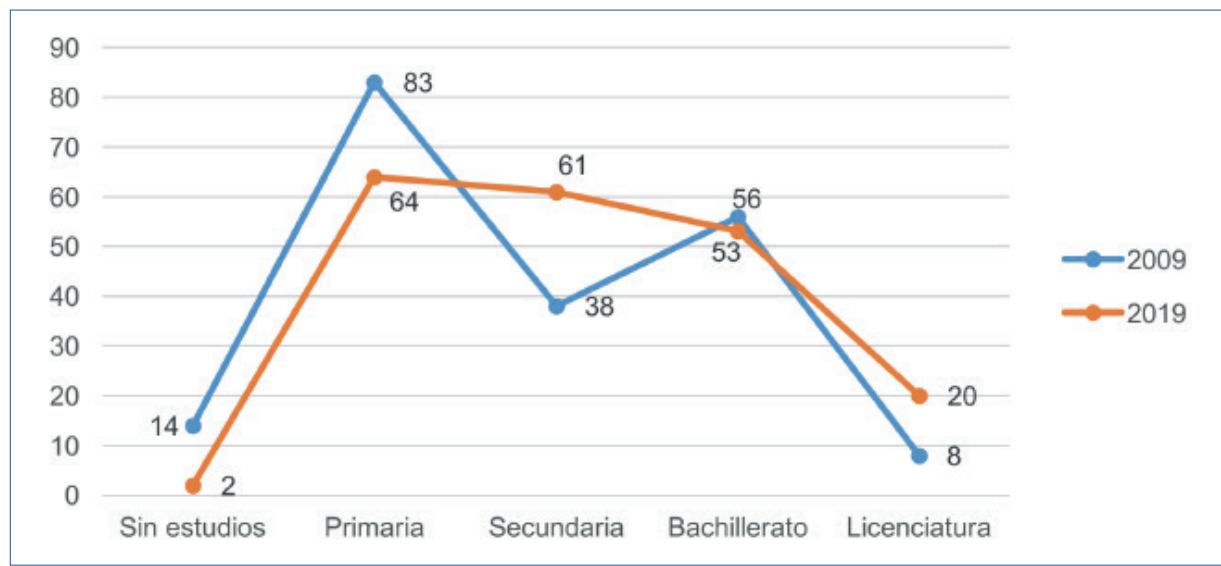

Fuente: Elaboración propia.

En cuanto a la ocupación de las personas encuestadas del 2009 al 2019 se registraron incrementos en la dedicación al trabajo independiente y como empleadas. Lo anterior tiene relación con la incorporación de las mujeres al trabajo remunerado ya sea emprendiendo un negocio de manera independiente o como empleadas. En el 2019 los trabajos independientes que realizan los hombres son como campesinos, comerciantes o ganaderos (Gráfico No.2).

Gráfica N. 2: Ocupación de las personas encuestadas.

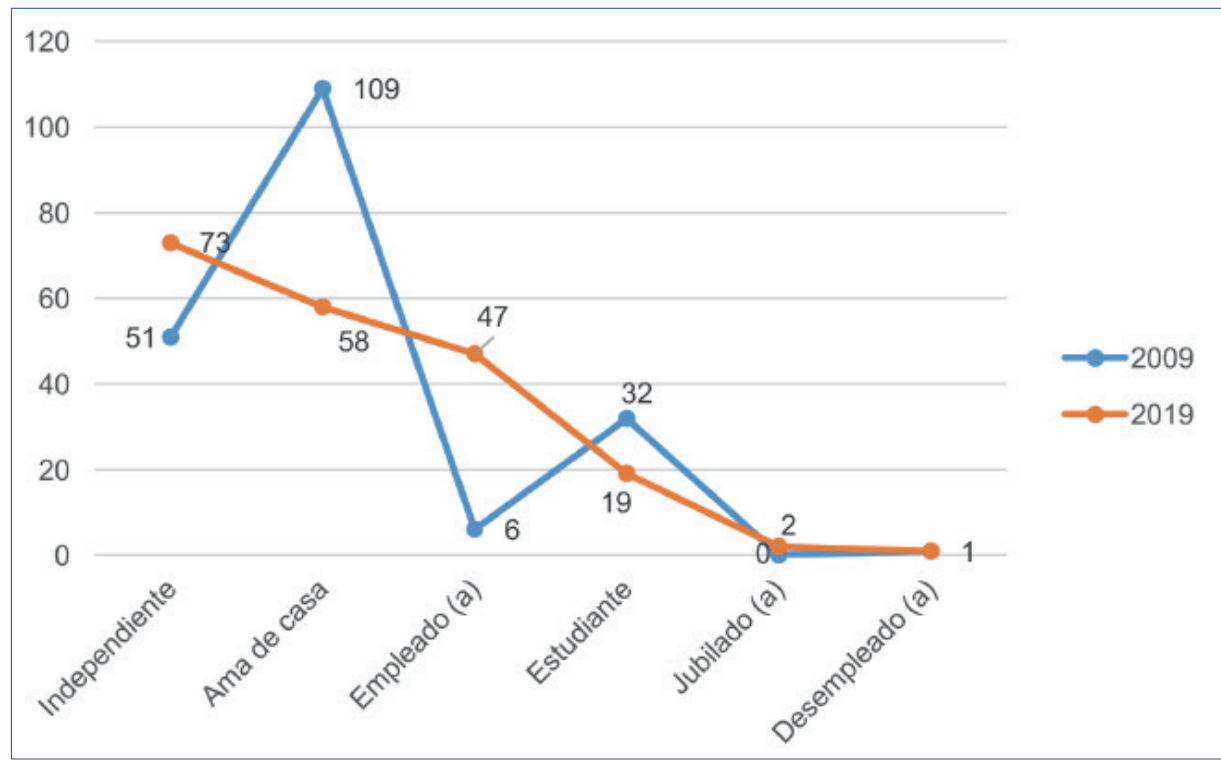

Fuente: Elaboración propia.

De las respuestas obtenidas por parte de los habitantes de la localidad se obtuvo la lista de los elementos (ítems) que surgieron de las afirmaciones individuales de cada uno de los expertos, arrojaron en total 33 problemas en el 2009 (Tabla N. ${ }^{\circ}$ 3). La escala de decisiones indica que las opiniones donde: Verde oscuro es un problema muy grave, verde claro es un problema grave, amarillo es un problema en transición o indecisión, rosa es un problema poco importante, rojo es un problema sin importancia o no hay problema. 
Tabla N. ${ }^{\circ}$ 3: Problemas detectados por importancia en 2009.

\begin{tabular}{|c|c|c|}
\hline PROBLEMA & Frecuencia & Urgencia \\
\hline 1.- Seguridad Pública & 113 & 26 \\
\hline 2.- Arreglo de calles & 164 & 25 \\
\hline 3.- Alumbrado público & 106 & 11 \\
\hline 4.- Agua potable & 126 & 56 \\
\hline 5.- Recolección de basura & 113 & 9 \\
\hline 6.- Servicios médicos & 99 & 33 \\
\hline 7.- Generación de fuentes de empleo & 31 & 3 \\
\hline 8.- Atención a inundaciones & 7 & 1 \\
\hline 9.- Construcción de un rastro & 4 & \\
\hline 10.- Construcción de una biblioteca & 1 & \\
\hline 11.- Renovación de la presidencia municipal & 7 & \\
\hline 12.- Señal de televisión & 5 & \\
\hline 13.- Vandalismo & 1 & \\
\hline 14.- Apoyo a instituciones educativas & 28 & 7 \\
\hline 15.- Ampliación de la carretera & 5 & \\
\hline 16.- Creación de espacios deportivos & 12 & \\
\hline 17.- Saneamiento de lotes baldíos & 9 & \\
\hline 18.- Semaforización de la carretera & 1 & \\
\hline 19.- Organización social & 1 & 1 \\
\hline 20.- Instalación de un banco & 3 & \\
\hline 21.- Transporte público local & 3 & \\
\hline 22.- Tala de arbolado urbano & 1 & \\
\hline 23.- Líneas telefónicas particulares & 3 & \\
\hline 24.-Apoyos gubernamentales & 2 & 1 \\
\hline 25.- Drogadicción & 1 & \\
\hline 26.- Combate eficaz al dengue & 7 & 1 \\
\hline 27.-Teléfonos públicos & 2 & \\
\hline 28.- Robos & 1 & \\
\hline 29.- Conserje & 1 & \\
\hline 30.- Ampliación de red eléctrica & 2 & \\
\hline 31.- Vandalismo en ranchos & 1 & \\
\hline 32.- Instalación del drenaje y tratamiento de aguas residuales & 134 & 25 \\
\hline 33.- Autódromo & 1 & \\
\hline
\end{tabular}

Fuente: Elaboración propia.

En el 2019 la lista de problemas enlistados por importancia fue de 34 a partir de las respuestas de las personas encuestadas (Tabla N. ${ }^{\circ}$ ), los cambios más significativos fueron en los problemas con bajas frecuencias o que no representan urgencia. La escala de colores es la misma que se utilizó en 2009. 
Tabla N. ${ }^{\circ}$ 4: Problemas detectados por importancia en 2019.

\begin{tabular}{|c|c|c|}
\hline PROBLEMA & Frecuencia & Urgencia \\
\hline 1.- Seguridad Pública & 31 & 5 \\
\hline 2.- Arreglo de calles & 166 & 42 \\
\hline 3.- Alumbrado público & 42 & 2 \\
\hline 4.- Agua potable & 181 & 60 \\
\hline 5.- Recolección de basura & 114 & 8 \\
\hline 6.- Servicios médicos & 104 & 8 \\
\hline 7.- Generación de fuentes de empleo & 33 & 9 \\
\hline 8.- Atención a inundaciones & 12 & 3 \\
\hline 9.- Falta de topes en la carretera Federal 200 & 1 & \\
\hline 10.- Construcción de una biblioteca & 1 & \\
\hline 11.- Arreglo de las brechas & 19 & \\
\hline 12.- Instalar baños públicos & 4 & \\
\hline 13.- Construir un Centro Universitario & 2 & \\
\hline 14.- Apoyo a instituciones educativas & 7 & 1 \\
\hline 15.- Arreglo del Jardín "Plaza de Armas" & 9 & \\
\hline 16.- Creación de espacios deportivos & 59 & 6 \\
\hline 17.- Accesos a poblaciones, río y playas & 2 & \\
\hline 18.- Falta de vivienda digna & 2 & \\
\hline 19.- Organización social & 9 & 6 \\
\hline 20.- Instalación de un banco & 2 & \\
\hline 21.- Falta de servicios del DIF & 1 & \\
\hline 22.- Falta de cultura ambiental & 1 & \\
\hline 23.- Líneas telefónicas particulares & 2 & \\
\hline 24.-Apoyos gubernamentales & 3 & \\
\hline 25.- Drogadicción & 2 & \\
\hline 26.- Combate eficaz al dengue & 7 & \\
\hline 27.-Impulsar a actividades culturales & 5 & \\
\hline 28.- Gasolineras reguladas & 5 & \\
\hline 29.- Mejorar servicios de Internet & 2 & \\
\hline 30.- Ampliación de red eléctrica & 8 & \\
\hline 31.- Contar con Farmacias 24 hrs. & 1 & \\
\hline 32.- Instalación del drenaje y tratamiento de aguas residuales & 161 & 50 \\
\hline 33.- Autódromo Más tiendas & 1 & \\
\hline 34.- Falta de una fábrica de hielo & 1 & \\
\hline
\end{tabular}

Fuente: Elaboración propia.

Después de identificados los problemas importantes se procedió al análisis de prioridad para resolver los problemas dependiendo de la urgencia que representan para la persona encuestada, por lo que se seleccionaron los 12 problemas más urgentes por resolver según las personas encuestadas. En el 2009 los problemas sólo correspondieron a los primeros tres colores de la escala (Tabla N. ${ }^{0} 5$ ). 
Tabla N. ${ }^{\circ}$ 5: Problemas detectados por urgencia en 2009.

\begin{tabular}{|l|l|l|}
\hline \multicolumn{1}{|c|}{ PROBLEMA } & \multicolumn{1}{|c|}{ Frecuencia } & \multicolumn{1}{c|}{$\begin{array}{c}\text { No. de } \\
\text { Prioridad }\end{array}$} \\
\hline 4.- Agua potable & 126 & 1 \\
\hline 6.- Servicios médicos & 99 & 2 \\
\hline 1.- Seguridad Pública & 113 & 3 \\
\hline 2.- Arreglo de calles & 164 & 4 \\
\hline 32.- Instalación del drenaje y tratamiento de aguas residuales & 134 & 5 \\
\hline 3.- Alumbrado público & 106 & 6 \\
\hline 5.- Recolección de basura & 113 & 7 \\
\hline 14.- Apoyo a instituciones educativas & 28 & 8 \\
\hline 8.- Atención a inundaciones & 7 & 9 \\
\hline 19.- Organización social & 1 & 10 \\
\hline 24.-Apoyos gubernamentales & 2 & 11 \\
\hline 7.- Generación de fuentes de empleo & 31 & 12 \\
\hline
\end{tabular}

Fuente: Elaboración propia.

En 2019 se presentó la variación en la ampliación a cuatro de los cinco colores de la escala correspondiente, por lo que 2 de los 12 problemas corresponden a problemas poco importantes (Tabla N. ${ }^{\circ} 6$ ).

Tabla N. ${ }^{\circ}$ 6: Problemas detectados por urgencia en 2019.

\begin{tabular}{|l|c|c|}
\hline \multicolumn{1}{|c|}{ PROBLEMA } & Frecuencia & $\begin{array}{c}\text { No. de } \\
\text { Prioridad }\end{array}$ \\
\hline 4.- Agua potable & 181 & 1 \\
\hline 32.- Instalación del drenaje y tratamiento de aguas residuales & 161 & 2 \\
\hline 2.- Arreglo de calles & 166 & 4 \\
\hline 7.- Generación de fuentes de empleo & 33 & 5 \\
\hline 19.- Organización social & 9 & 6 \\
\hline 1.- Seguridad Pública & 31 & 7 \\
\hline 3.- Alumbrado público & 42 & 8 \\
\hline 16.- Creación de espacios deportivos & 59 & 9 \\
\hline 8.- Atención a inundaciones & 12 & 10 \\
\hline 14.- Apoyo a instituciones educativas & 7 & 11 \\
\hline 11.- Arreglo de las brechas & 19 & 12 \\
\hline 26.- Combate eficaz al dengue & 7 & 4 \\
\hline
\end{tabular}

Fuente: Elaboración propia.

El análisis final de los problemas sociales percibidos por los pobladores de la comunidad consistió en elaborar la matriz estructural en la que se retomaron los 10 problemas prioritarios detectados, 
se procedió a compararlos entre ellos con el propósito de identificar sus posibles relaciones; dándole valor de 1 si existe relación y 0 cuando no la exista (la suma representa la dependencia total entre los problemas).

En el 2009 el problema con mayor interrelación fue el número 10: la organización social con la sumatoria de dependencia de 17, ya que se consideró que se relacionaba con el resto de problemas. Los siguientes problemas con mayor interrelación fueron: arreglo de las calles (problema número 4), servicios médicos (problema número 2) y la instalación del drenaje y tratamiento de aguas residuales (problema número 5) (Tabla N. ${ }^{\circ}$ ).

Tabla N. ${ }^{0}$ 7: Matriz estructural de los problemas prioritarios en 2009.

\begin{tabular}{|c|c|c|c|c|c|c|c|c|c|c|c|c|c|}
\hline $\begin{array}{c}\text { No. de } \\
\text { Prioridad } \\
\text { del } \\
\text { Problema }\end{array}$ & $\mathbf{1}$ & $\mathbf{2}$ & $\mathbf{3}$ & $\mathbf{4}$ & $\mathbf{5}$ & $\mathbf{6}$ & $\mathbf{7}$ & $\mathbf{8}$ & $\mathbf{9}$ & $\mathbf{1 0}$ & Suma & $\begin{array}{c}\text { \% en } \\
\text { Y }\end{array}$ & Suma \\
\hline 1 & 8 & 1 & 0 & 1 & 1 & 0 & 0 & 0 & 0 & 1 & 4 & 7.84 & 15.68 \\
\hline 2 & 1 & 10 & 0 & 1 & 1 & 0 & 1 & 0 & 1 & 1 & 6 & 11.76 & 19.6 \\
\hline 3 & 0 & 0 & 4 & 0 & 0 & 1 & 0 & 0 & 0 & 1 & 2 & 3.92 & 7.84 \\
\hline 4 & 1 & 0 & 0 & 11 & 1 & 1 & 0 & 0 & 1 & 1 & 5 & 9.8 & 21.56 \\
\hline 5 & 1 & 0 & 0 & 1 & 10 & 0 & 1 & 0 & 1 & 1 & 5 & 9.8 & 19.6 \\
\hline 6 & 0 & 0 & 1 & 1 & 0 & 6 & 0 & 0 & 0 & 1 & 3 & 5.88 & 11.76 \\
\hline 7 & 0 & 1 & 0 & 0 & 0 & 0 & 5 & 0 & 0 & 1 & 2 & 3.92 & 9.8 \\
\hline 8 & 0 & 0 & 0 & 0 & 0 & 0 & 0 & 1 & 0 & 1 & 1 & 1.96 & 1.96 \\
\hline 9 & 0 & 1 & 0 & 1 & 1 & 0 & 0 & 0 & 8 & 1 & 4 & 7.84 & 15.68 \\
\hline 10 & 1 & 1 & 1 & 1 & 1 & 1 & 1 & 0 & 1 & 17 & 8 & 15.68 & 33.32 \\
\hline Suma & 4 & 4 & 2 & 6 & 5 & 3 & 3 & 0 & 4 & 9 & 40 & & \\
\hline$\%$ en X & 7.84 & 7.84 & 3.92 & 11.76 & 9.8 & 5.88 & 5.88 & 0 & 7.84 & 17.64 & & & \\
\hline
\end{tabular}

Fuente: Elaboración propia.

En 2019 la organización social prevaleció como el problema con mayor interrelación (problema número 5), con una sumatoria de dependencia de 16 con respecto a los otros problemas mencionados. Asimismo, el siguiente problema fue el arreglo de las calles (problema número 3); la instalación del drenaje y el tratamiento de aguas residuales (problema número 2), el cambio más significativo fue el problema de agua potable (problema número 1) el cual obtuvo la misma interrelación y dependencia que el problema número 2 (Tabla N. ${ }^{\circ} 8$ ). 
Tabla N. ${ }^{\circ}$ 8: Matriz estructural de los problemas prioritarios en 2019.

\begin{tabular}{|c|c|c|c|c|c|c|c|c|c|c|c|c|c|}
\hline $\begin{array}{c}\text { No. de } \\
\text { Prioridad } \\
\text { del } \\
\text { Problema }\end{array}$ & $\mathbf{1}$ & $\mathbf{2}$ & $\mathbf{3}$ & $\mathbf{4}$ & $\mathbf{5}$ & $\mathbf{6}$ & $\mathbf{7}$ & $\mathbf{8}$ & $\mathbf{9}$ & $\mathbf{1 0}$ & Suma & $\begin{array}{c}\text { \% en } \\
\mathbf{Y}\end{array}$ & $\mathbf{S u m a}$ \\
\hline 1 & 8 & 1 & 0 & 1 & 1 & 0 & 0 & 0 & 0 & 1 & 4 & 7.84 & 15.68 \\
\hline 2 & 1 & 8 & 1 & 0 & 1 & 0 & 0 & 0 & 1 & 0 & 4 & 7.84 & 15.68 \\
\hline 3 & 1 & 1 & 9 & 0 & 1 & 0 & 1 & 0 & 1 & 0 & 5 & 9.8 & 17.64 \\
\hline 4 & 1 & 0 & 0 & 7 & 1 & 1 & 0 & 0 & 1 & 1 & 5 & 9.8 & 13.72 \\
\hline 5 & 1 & 1 & 1 & 0 & 16 & 1 & 1 & 1 & 1 & 0 & 7 & 13.72 & 31.36 \\
\hline 6 & 0 & 0 & 0 & 0 & 1 & 5 & 1 & 0 & 0 & 0 & 2 & 3.92 & 9.8 \\
\hline 7 & 0 & 0 & 1 & 0 & 1 & 1 & 6 & 0 & 0 & 0 & 3 & 5.88 & 11.76 \\
\hline 8 & 0 & 0 & 0 & 0 & 1 & 0 & 0 & 2 & 0 & 0 & 1 & 1.96 & 3.92 \\
\hline 9 & 0 & 1 & 1 & 0 & 1 & 0 & 0 & 0 & 7 & 0 & 3 & 5.88 & 13.72 \\
\hline 10 & 0 & 0 & 0 & 1 & 1 & 0 & 0 & 0 & 0 & 4 & 2 & 3.92 & 7.84 \\
\hline Suma & 4 & 4 & 4 & 2 & 9 & 3 & 3 & 1 & 4 & 2 & 36 & & \\
\hline$\%$ en X & 7.84 & 7.84 & 7.84 & 3.92 & 17.64 & 5.88 & 5.88 & 1.96 & 7.84 & 3.92 & & & \\
\hline
\end{tabular}

Fuente: Elaboración propia.

El porcentaje obtenido para cada uno de los problemas en las matrices estructurales, permitió conocer la zona en la que se ubican los 10 problemas prioritarios detectados en ambos años. En 2009 como problemas autónomos se ubicaron: seguridad pública (problema 3), alumbrado público (problema 6), recolección de basura (problema 7) y apoyos a instituciones educativas (problema 8), éste último es el problema con menor influencia en el resto de problemas detectados en la matriz estructural. En la línea entre la zona de problemas autónomos y la zona de los problemas de poder se ubicaron dos problemas: el agua potable (problema 1) y la atención a inundaciones (problema 9). En el cuadrante de la zona de poder se encontró el problema de: servicios médicos (problema 2). En la zona de conflicto estuvieron tres problemas: arreglo de calles (problema 4), instalación de drenaje y tratamiento de aguas residuales (problema 5) y la organización social (problema 10); los primeros dos problemas de esta zona presentan el mismo nivel de influencia con respecto a los problemas autónomos y de poder relacionados en la matriz estructural. Sin embargo, el problema 4 tiene una mayor dependencia, es decir, para que las calles sean funcionales debería considerarse solucionar los problemas: 1, 5, 6 y 9. El problema con mayor dependencia e influencia en el resto de problemas es la organización social (problema 10), ya que sí se logrará la participación y el consenso social sería posible primero solucionar problemas autónomos de baja influencia y dependencia -como gestionar los apoyos para instituciones educativas-, para luego escalar en la solución de problemas de mayor complejidad (Gráfica N. ${ }^{\circ}$ 3). 


\section{Gráfica N. ${ }^{\circ}$ 3: Matriz de Influencia-Dependencia de los Problemas Prioritarios en 2009.}

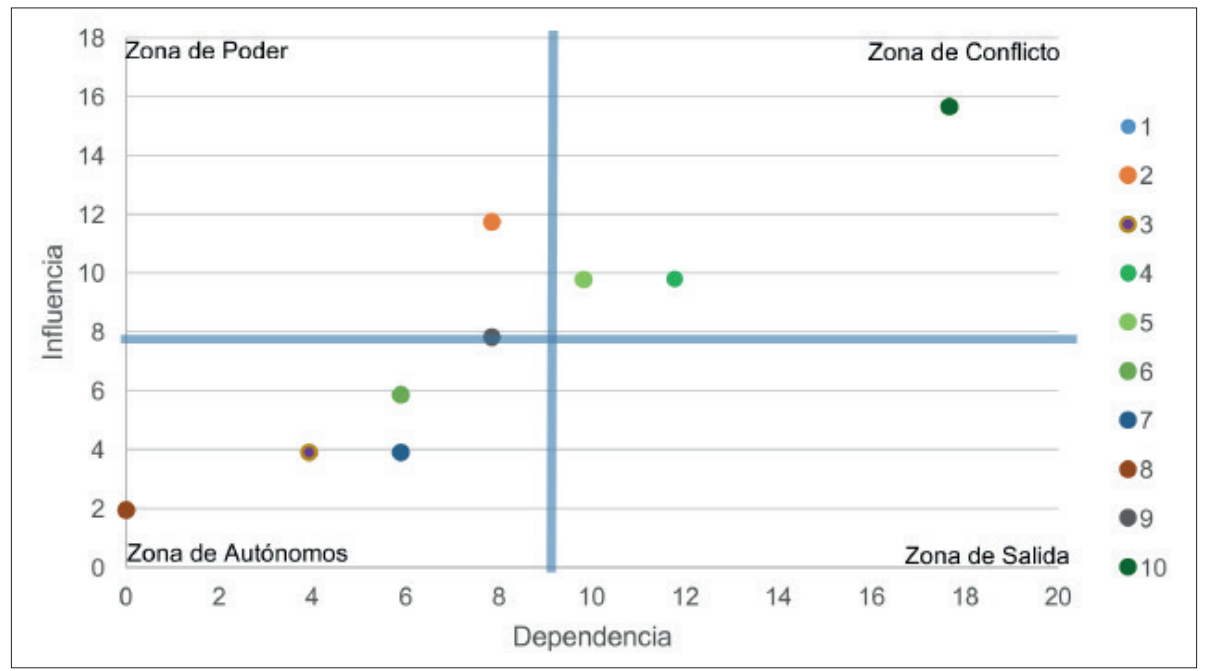

Fuente: Elaboración propia.

En 2019 como problemas autónomos se ubicaron: seguridad pública (problema 6), alumbrado público (problema 7), creación de espacios deportivos (problema 8), atención a inundaciones (problema 9) y apoyo a instituciones educativas (problema 10), en este año el problema con menor influencia en el resto de problemas detectados fue el problema 8. En la zona de poder se ubicaron los problemas: agua potable (problema 1), instalación de drenaje y tratamiento de aguas residuales (problema 2), arreglo de calles (problema 3) y generación de fuentes de empleo (problema 4). Y en la zona de conflicto sólo se ubicó un problema: la organización social (problema 5), por lo cual en el lapso de diez años persiste como el problema de mayor dependencia e influencia en el resto de problemas detectados por la comunidad (Gráfica No. 4).

\section{Gráfica N. 4: Matriz de Influencia-Dependencia de los Problemas Prioritarios en 2019.}

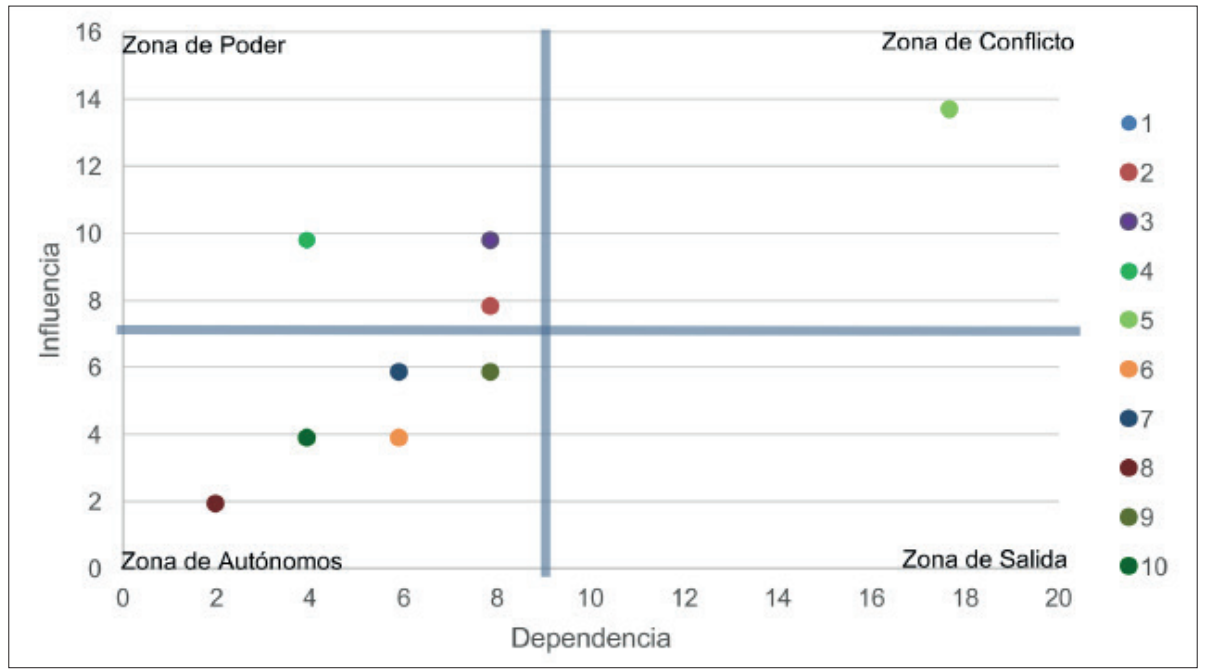

Fuente: Elaboración propia. 
Con relación a la información que proporcionaron los pobladores acerca de sí recibían visitantes, en el 2009 el 35\% respondió que no, por lo que el 65\% restante afirmó que recibía familiares o amigos que pasaban su tiempo de descanso en la localidad. En 2019 disminuyó a 61\% de las personas que afirmaron que recibían familiares o amigos que los visitaban durante sus vacaciones.

La gran mayoría de los visitantes en 2009 provenían de otros Municipios, entre los que sobresalen: Guadalajara, Zapotiltic y Ciudad Guzmán. Le siguen los visitantes que provienen de otro Estado de la república, el estado que más mencionaron fue Michoacán. Los que reciben visitantes extranjeros representan el 14\%, en su mayoría son familiares que emigraron a Estados Unidos de América en busca de oportunidades laborales. En 2019 los visitantes provienen principalmente de Guadalajara, Puerto Vallarta y Manzanillo. Y el Estado que más aludieron fue Colima, seguido de Michoacán. Con respecto a las personas que reciben familiares o amigos provenientes de Estados Unidos de América representó el 18\%, cuatro puntos porcentuales más con respecto al 2009 (Gráfica N. ${ }^{\circ}$ 5).

\section{Gráfica N. ${ }^{\circ}$ 5: Origen de los visitantes que reciben los habitantes de José María Morelos en el 2019.}

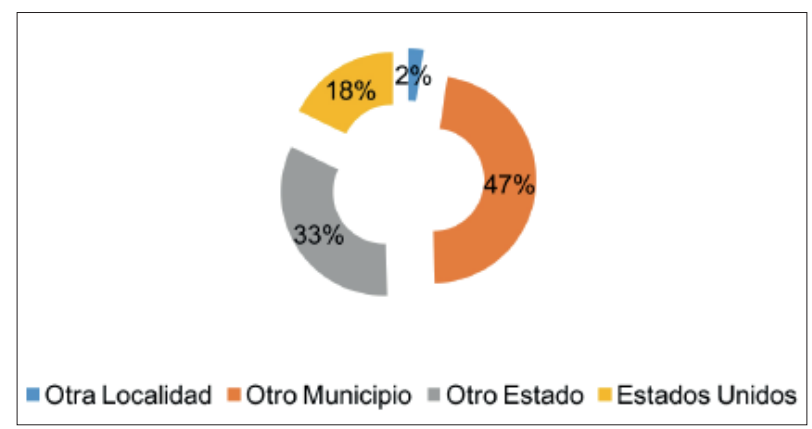

Fuente: Elaboración propia.

Acerca de la disponibilidad de prestar servicios turísticos en el 2009, el 69\% de los encuestados afirmó estar dispuesto a prestar algún servicio al turismo; de éstos, el $25 \%$, manifestó interés por ser guía de turistas; el 12\% se interesó en el comercio de artesanías y productos de la región. Seguidos por la oferta de servicios de alimentación y alojamiento. En el 2019 se incrementó al 76\% de las personas interesadas en prestar servicios al turismo con una marcada tendencia hacía la atención como guía, servicios de alimentación o alojamiento (Grafica N. ${ }^{\circ}$ 6).

Gráfica N. ${ }^{\circ}$ 6: Preferencias de los habitantes acerca de la prestación de servicios turísticos en el 2009 y el 2019.

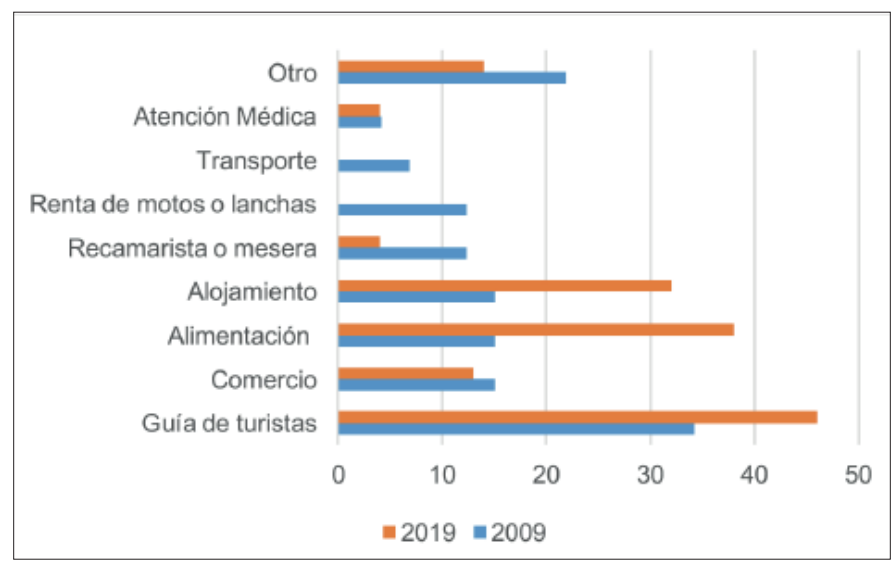

Fuente: Elaboración propia. 
En 2009, el 57\% de las personas encuestadas contestaron que el trabajo o el empleo es el beneficio más relacionado con el turismo, el $21 \%$ contestó que la derrama económica (dinero) por la compra-venta de tierras y, el tercer grupo, por orden de importancia, contestó que ningún beneficio percibían del turismo hacia la localidad (Gráfica N. ${ }^{\circ} 7$ ).

Gráfica N.ำ 7: Beneficios percibidos del turismo hacia la localidad en el 2009.

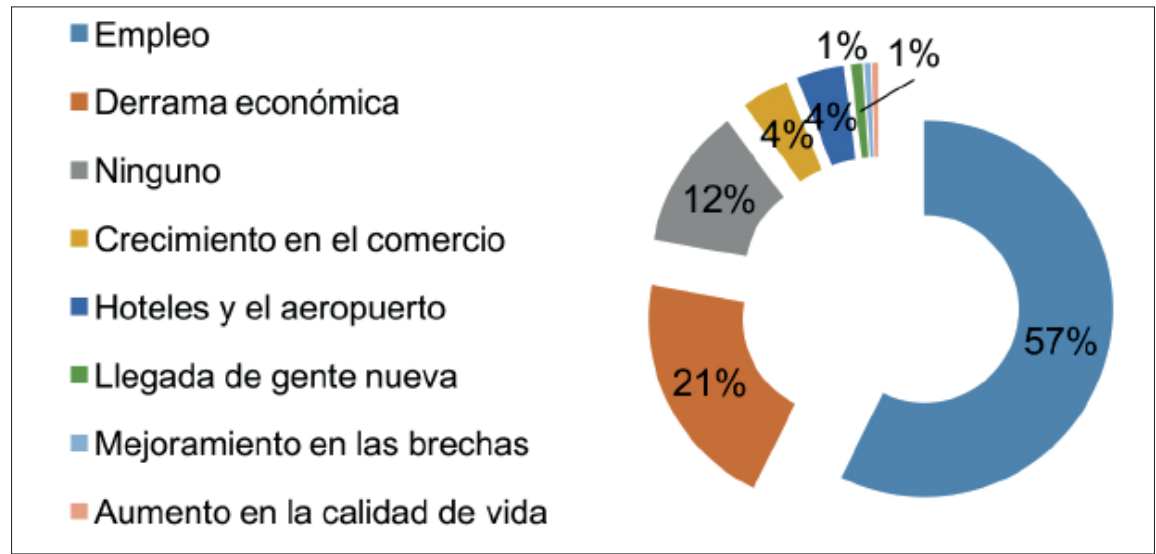

Fuente: Elaboración propia.

En el 2019 persistió la tendencia de que el principal beneficio del turismo es el trabajo o el empleo, sin embargo, registró un descenso de 5 puntos porcentuales. La derrama económica siguió en la segunda posición y registró un ascenso de 16 puntos porcentuales, por el contrario, la opinión de que no reciben ningún beneficio del turismo disminuyó 9 por ciento (Gráfica N. ${ }^{\circ} 8$ ).

Gráfica N. ${ }^{\circ}$ 8: Beneficios percibidos del turismo hacia la localidad en el 2019.

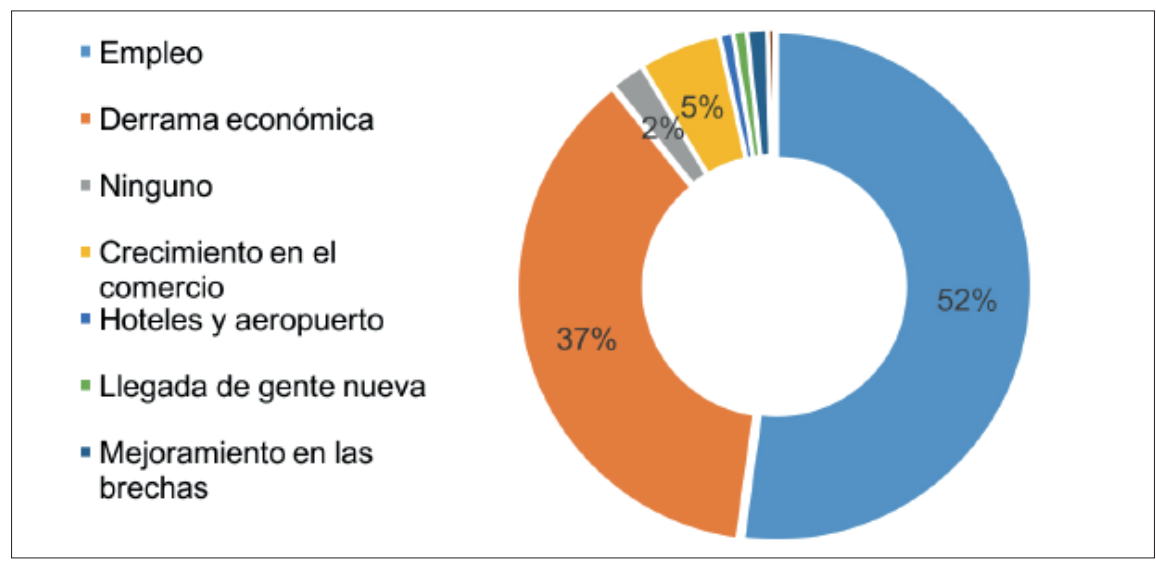

Fuente: Elaboración propia.

En lo que se refirió a los impactos negativos del turismo percibidos por las personas encuestadas, en el 2009, el $56 \%$ no consideró que el turismo perjudicará a la localidad, el $2 \%$ no contestó y el $42 \%$ mencionó por lo menos un aspecto negativo del turismo. El impacto ambiental o contaminación fue el impacto negativo que señalaron con mayor frecuencia, le sigue la inseguridad y la privatización de la playa (Gráfica N. ${ }^{\circ}$ 9). 
Gráfica N. ${ }^{\circ}$ 9: Posibles impactos negativos percibidos del turismo hacia la localidad en el 2009.

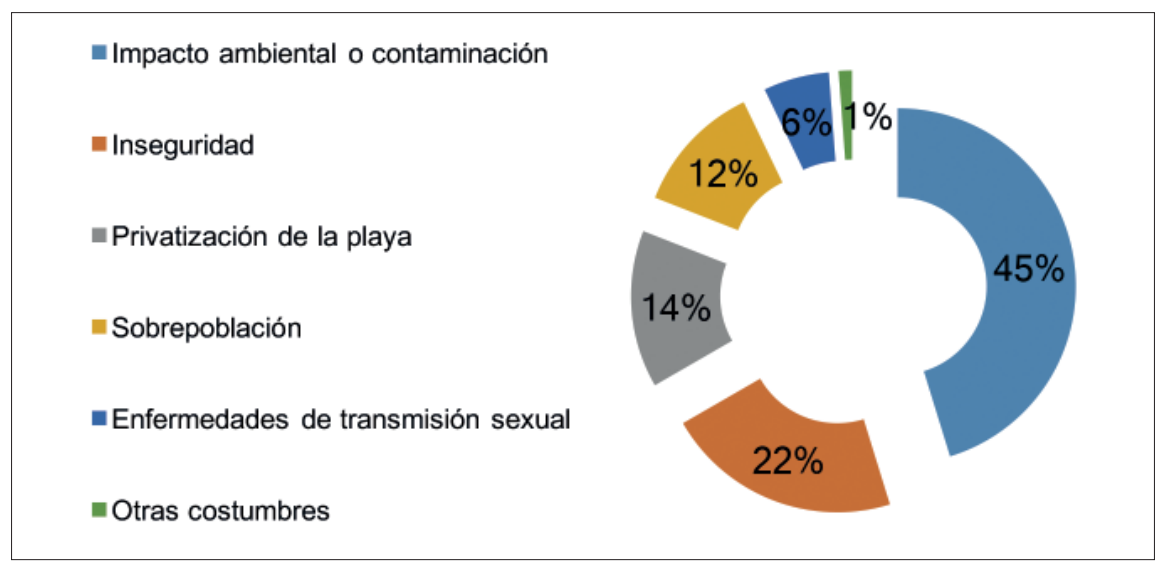

Fuente: Elaboración propia.

En 2019. el 40\% de las personas encuestadas -dieciséis puntos porcentuales menos con respecto al 2009- consideró que el turismo no causaría algún impacto negativo a la localidad, el $60 \%$ restante por lo menos mencionó un impacto negativo que percibía relacionado con la actividad turística. Con respecto al 2009 se incrementaron los impactos negativos relacionados con la actividad turística que perciben las personas encuestadas. La contaminación o el impacto ambiental incrementó su tendencia -cinco puntos porcentuales más con respecto al 2009-, seguido de la inseguridad, la privatización de la playa y la sobrepoblación. En particular, las personas encuestadas en 2019 comentaron que la sospecha de la privatización de la playa Chalacatepec se vincula con los conflictos ejidales, ya que manifestaron que existen dos grupos al interior del Ejido, uno a favor absoluto para que se ejecuten el Desarrollo Vistas y la aeropista y; otro grupo que solicita se respeten: las regulaciones vigentes aplicables a cada proyecto y sus derechos agrarios como ejidatarios (Gráfica N. $\left.{ }^{\circ} 10\right)$.

\section{Gráfica N. ${ }^{\circ}$ 10: Posibles impactos negativos percibidos del turismo hacia la localidad en el 2009.}

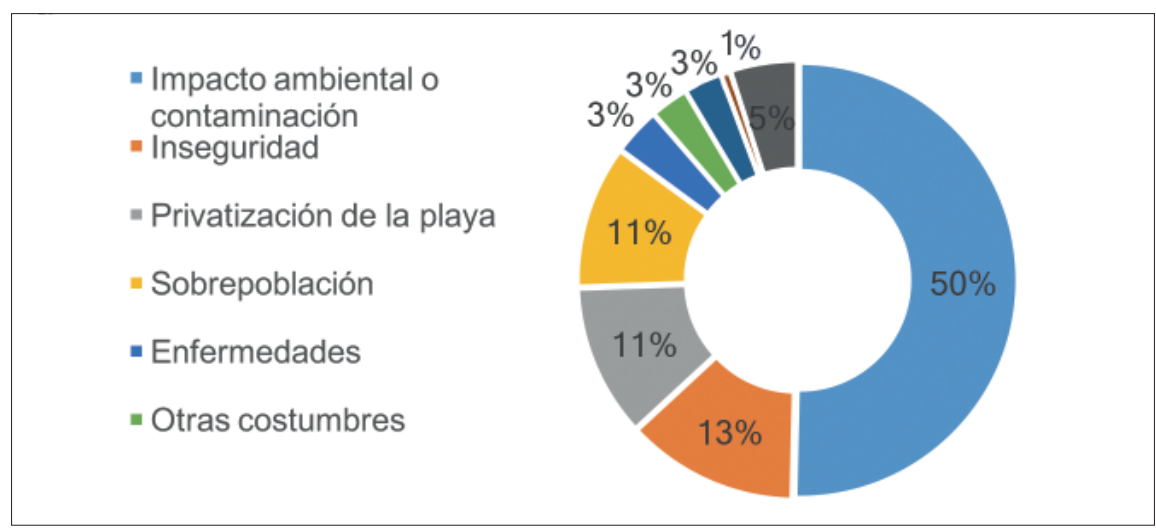

Fuente: Elaboración propia.

De las opiniones y comentarios que realizaron las personas encuestadas, se registraron preocupaciones relacionadas con actividades ilícitas como: crimen organizado, venta de drogas, desapariciones, secuestros y amenazas. Además, de advertir la presencia de un mayor número de cocodrilos en el río San Nicolás y la Laguna Chalacatepec. 


\section{Discusión y conclusiones}

La Costa Alegre y el municipio de Tomatlán han sido objeto de estudio de numerosas investigaciones que abordan su diversidad biológica, los procesos sociales y actividades económicas. César y Arnaiz (2004) evidenciaron que en la costa de Jalisco era necesario superar la deficiencia en infraestructura y servicios públicos, así como la regularización de la tenencia de la tierra para desarrollar la prestación de servicios turísticos. Sin embargo, las diferentes administraciones públicas han desarrollado planes emergentes, a corto plazo, que no solucionan las carencias y, en algunos casos, agravan los problemas en las comunidades e incrementan las desigualdades entre lo urbano y lo rural; tal es el caso de la atención en los servicios de salud.

A nivel municipal, César y Arnaiz (2005) definieron que los principales problemas que tenía que enfrentar Tomatlán eran: la asimetría económica y social, marginación principalmente en las periferias, migraciones internas y externas en búsqueda de mejores empleos, educación, servicios de salud, las carencias de servicios públicos municipales como: el agua potable, la instalación del drenaje sanitario y pluvial, el tratamiento de las aguas residuales, recolección de residuos sólidos urbanos, mejorar las vialidades, la ausencia de seguridad pública y mejorar la imagen urbana; además de coadyuvar para que las personas posean la certeza de tenencia de la tierra ejidal, comunal o de pequeños propietarios.

A nivel federal, estatal y municipal se ha invertido para mejorar la infraestructura carretera, el proyecto más significativo es la ampliación de la carretera federal No. 200 Puerto Vallarta- Barra de Navidad, de dos a cuatro carriles en algunos tramos, además de la colocación de señalética necesaria para orientar a personas no residentes. Sin embargo, en el ámbito local de la comunidad de José María Morelos algunas personas encuestadas comentaron que con la ampliación de la carretera se generó un conflicto entre el Comisariado Ejidal y un ejidatario -ya que no se le liquidó el terreno por el cual pasa la carretera-, lo que culminó en la colocación de una puerta por parte del ejidatario en uno de los ingresos hacia el río San Nicolás -lugar que era visitado de forma frecuente por los pobladores para realizar actividades de baño o esparcimiento-, por lo que se adjudicó dicho terreno del camino como pago del tramo que se utilizó para la carretera.

Así pues, debe considerarse que en ocasiones los emprendimientos e inversiones ya sean públicas o privadas que buscan impulsar las actividades turísticas en los espacios rurales no alcanzan los resultados esperados, causando frustraciones y más aún pueden provocar efectos no deseados o impactos negativos en la población de acogida (Pulido Fernández, 2008).

Derivado de los resultados obtenidos es posible concluir que los problemas prioritarios según la opinión de los pobladores de la localidad:

En el 2009:

- Por importancia se consideraron: arreglo de calles e instalación del drenaje y tratamiento de aguas residuales.

- Por urgencia: agua potable y servicios médicos.

- Por motricidad: organización social.

En el 2019:

- Por importancia: agua potable y el arreglo de calles.

- Por urgencia: la instalación del drenaje y tratamiento de aguas residuales.

- Por motricidad: organización social.

En ambos años los problemas detectados por importancia y por urgencia son servicios básicos, que según la fracción III del artículo 115 de la Constitución de los Estados Unidos Mexicanos es función de la administración pública municipal garantizarlos (DOF, 2020). En el período de tiempo de diez años según la percepción de los pobladores no se evidencian cambios significativos en la infraestructura para el suministro de agua potable, el cual se ofrece una o dos veces por semana; la red de drenaje sanitario no cubre la demanda de las viviendas habitadas, además la planta de tratamiento de aguas residuales no trata la totalidad de la producción. Algunas calles han sido empedradas, sin embargo, la mayoría son calles de terracería y sin banquetas que en época de lluvias (de mayo a noviembre) son de difícil tránsito tanto para peatones como para vehículos.

En el año 2009, la generación de empleos fue un problema intermedio o en transición; para el año 2019, la generación de empleos se colocó como un problema grave en la localidad con una alta frecuencia, pero con baja urgencia para ser resuelto. Consideramos que para que el turismo sea una alternativa 
complementaria que atienda esta problemática, será necesaria la capacitación y formación para el trabajo que posibilite la prestación de servicios turísticos de calidad.

En 2009, la recolección de basura fue un problema que se ubicó en el cuadrante de problemas autónomos, aunque en el 2019 algunas personas lo mencionaron, no figuró como un problema ni importante ni urgente, muy probablemente porque con respecto al 2009 -que no se prestaba el servicio en la localidad- en el 2019 el camión recolector del gobierno municipal acude cuatro días por semana.

En el 2009 y 2019, el problema de mayor motricidad con alta influencia en los demás problemas y, del cual pueden depender el resto de problemas, es el problema de los conflictos relacionados con la organización social. En tanto se resuelva la organización social en las esferas barrial, ejidal, municipal, de cooperativas y asociaciones se solucionarán otros problemas que den impulso al desarrollo de infraestructura urbana para el mejoramiento de la calidad de vida de los habitantes. En situaciones de contingencia y desastre es cuando han surgido grupos auto-organizados desde la comunidad. En la temporada de ciclones tropicales del 2019, la localidad fue afectada directa por el paso de dos ciclones: Lorena y Narda. El segundo ocurrió en octubre y dejó daños en viviendas, fue necesario el rescate y evacuación de personas, ya que la parte baja de la localidad se inundó; por días se suspendieron los servicios de agua potable, drenaje y tratamiento de aguas residuales, los sistemas se colapsaron por completo.

Durante la visita del Gobernador del Estado, un grupo de pobladores afectados se organizó para evidenciar los problemas y afectaciones por los que estaban pasando. Además, fueron enérgicos en los reclamos y peticiones para que las autoridades de gobierno se coordinaran y, que los proyectos de infraestructura que se realizarán fueran de calidad con visión a largo plazo (PaniquiNews, 2019).

\section{Agradecimientos}

Se reconoce y agradece a las personas de la localidad José María Morelos por su amabilidad, apoyo y participación para la realización del trabajo de campo de la presente investigación.

Las autoras reconocen el apoyo del Centro Universitario de la Casta de la Universidad de Guadalajara (UDG) y en especial al Programa de Posgrado en Ciencias para el Desarrollo, la Sustentabilidad y el Turismo. Asimismo, al Consejo Nacional de Ciencia y Tecnología (CONACYT) del Gobierno de México.

\section{Bibliografía}

ACTUROP S. de R. L. de C. V. 2012. Manifestación de Impacto Ambiental del Proyecto Desarrollo Vistas. Manifestación de Impacto Ambiental Modalidad Regional.

AyMA Ingeniería y Consultoría S.A. C.V. 2006. Estudio para la Manifestación del Impacto Ambiental (MIA) de la Aeropista de Costalegre. Gobierno del Estado de Jalisco, Secretaría de Desarrollo Urbano, Guadalajara, Jalisco.

César Dachary, A., \& Arnaiz Burne, S. M. 2004. Desarrollo y Turismo en la Costa de Jalisco. Puerto Vallarta, Jalisco, México: Universidad de Guadalajara.

César Dachary, A., Arnaiz Burne, S. M., \& Otros. 2005. Turismo Rural: Modelos y Propuestas (Primera edición ed.). (A. César Dachary, \& S. M. Arnaiz Burne, Edits.) Puerto Vallarta, Jalisco, México: Universidad de Guadalajara.

Conferencia Mundial de Turismo Sostenible. 1995. Carta del Turismo Sostenible. Lanzarote, Islas Canarias.

DOF. 23 de Mayo de 1960. Resolución sobre el Nuevo Centro de Población Agrícola denominado José María Morelos. Diario Oficial de la Federación, CCXL(18), págs. 12-14.

DOF. 06 de Marzo de 2020. Constitución Política de los Estados Unidos Mexicanos. (C. d. Mexicanos, Ed.) Diario Oficial de la Federación, pág. 319. Obtenido de http://www.diputados.gob.mx/LeyesBiblio/ pdf/1_060320.pdf

Gobierno de Jalisco. 04 de Febrero de 2012. Programa Subregional de Desarrollo Turístico Costalegre, Estados de Jalisco. El Estado de Jalisco, Periódico Oficial, CCCLXXII(80921), págs. 1-45.

Godet, M. 2007. Prospectiva Estratégica: Problemas y Métodos. Cuadernos de LIPSOR, Segunda Edición(20).

INEGI. 2011. Censo de Población y Vivienda 2010, Principales Resultados por Localidad (ITER). México: INEGI. 
INEGI. 2016. Conociendo Jalisco (Sexta ed.). (I. N. Geografía, Ed.) México: Instituto Nacional de Estadística y Geografía.

Levin, R. I., \& Rubin, D. S. 1996. Estadística para Administradores (6a ed.). (Á. H. Flores Samaniego, Trad.) Naucalppan, Estado de México, México: Prentice-Hall Inc.

OMT. 03 de Febrero de 2011. Organización Mundial del Turismo. Recuperado el 04 de Febrero de 2011, de http://85.62.13.114/media/news/sp/press_det.php?id=7422\&idioma=S

PaniquiNews. 03 de Octubre de 2019. Visita el Gobernador Enrique Alfaro Ramírez a José María Morelos. Recuperado el 03 de Octubre de 2019, de PaniquiNews: https://www.facebook.com/watch/ live/?v=418728642118327\&ref=watch_permalink

Pulido Fernández, J. I. 2008. El Turismo Rural: Estructura económica y configuración territorial en España. Madrid, España: Síntesis.

Villanueva, L. Enero de 2000. El turismo sustentable en México: Un importante reto de la globalización. Recuperado el 6 de Enero de 2019, de http://fama2.us.es:8080/turismo/turismonet1/economia\%20 del\%20turismo/turismo\%20sostenible/turismo\%20sustentable\%20en\%20Mexico.pdf

Wearing, S., \& Neil, J. 2000. Ecoturismo: Impacto, tendencias y posibilidades (Primera ed.). (V. M. Medina, Trad.) Madrid, España: Síntesis. 